\title{
hydra
}

\section{O “ABORTO” DE JÚLIO PRESTES NA CAMPANHA PRESIDENCIAL DE 1929-1930}

\author{
Jefferson de Almeida Pinto 1 \\ Marcela Fernandes da Silva ${ }^{2}$ \\ Gabriella Machado Neves Santos 3
}

Resumo: Este artigo analisa e avalia como o debate religioso estava presente durante a campanha presidencial de 1929-1930, e suas influências na candidatura de Júlio Prestes e de Getúlio Vargas. O candidato da oligarquia paulista à presidência, Júlio Prestes, foi acusado de não estar condizente com os interesses da família brasileira e da lgreja. A imprensa brasileira teve uma importante função nesse contexto, uma vez que as informações alcançavam a população por meio dos veículos de comunicação da época. Nesse cenário, ficam evidentes as questões religiosas e suas relações com a família, o divórcio, a política e a influência midiática.

Palavras-chave: Divórcio; campanha presidencial; Júlio Prestes.

\section{JÚLIOPRESTES’S “ABORTION”INTHE 1929-1930PRESIDENTIAL CAMPAIGN}

\begin{abstract}
This article analyzes and assesses how present the religious debate was during the 1929-1930 presidential campaign and its influences on Júlio Prestes's and Getúlio Vargas's candidacy. The candidate to presidency backed by the paulista oligarchy, Júlio Prestes, was accused of not being aligned with the interests of the Brazilian family and the church. The Brazilian press had an important function in this context since information reached the population through communication vehicles from the period. In this scenario, religious issues and their relations to families, divorce, politics, and media influence are evident.
\end{abstract}

Keyword: Divorce; presidential campaign; Júlio Prestes.

\footnotetext{
1 Doutor em História pela Universidade Federal Fluminense e professor do Instituto Federal do Sudeste de Minas Gerais - Campus Juiz de Fora. Lattes: http://lattes.cnpq.br/5986501 1682801 13. E-mail: jefferson.pinto@ifsudestemg.edu.br.

2 Bolsista de Iniciação Científica do Conselho Nacional de Desenvolvimento Científico e Tecnológico (CNPq). Lattes: http://lattes.cnpq.br/9194224617504831.

3 Bolsista de Iniciação Científica do Conselho Nacional de Desenvolvimento Científico e Tecnológico (CNPq). Lattes: http://lattes.cnpq.br/9212833944869091.
} 


\section{hydra}

\section{Introdução}

Não é de hoje que os estudos a respeito da ruptura política ocorrida no Brasil e que levaria a uma "nova" oligarquia ao poder tem direcionado os interesses de estudiosos e historiadores. Mas já não é mais aceita a explicação de que o movimento ocorrido em 1930 por uma briga entre as oligarquias de São Paulo e de Minas Gerais colocou fim à chamada "política do café-comleite", inclusive porque o acordo político que teria sido realizado ainda nos tempos do governo Campos Sales, e que propunha um revezamento no poder republicano entre paulistas e mineiros, nunca chegou a ser proposto.

Atualmente, é investigada e discutida a existência de um jogo político muito denso e disputado, no qual várias oligarquias - além de São Paulo e Minas Gerais - também almejavam a indicação e composição das chapas para os pleitos eleitorais, como seriam os casos do próprio Rio Grande do Sul, do Rio de Janeiro, da Bahia e de Pernambuco4.

Outra vertente explicativa para o que teria ocorrido em 1930 diz respeito ao movimento tenentista. A década de 1920 foi marcada por uma grande agitação no campo econômico, político e social. Os anos subsequentes à primeira guerra foram vividos por novos atores, espalhados sobretudo pelas áreas urbanas, tendo em vista o pequeno incremento que o setor industrial teve naquele período, onde os sindicatos e o operariado iniciariam seu vasto repertório de lutas. Por outro lado, setores da elite agrária se viram às voltas, mais uma vez, com as instabilidades do mercado externo e com a necessidade de se pensar em políticas que valorizassem a produção cafeeira, fato comum se observarmos o período da primeira República e políticas como o Convênio de Taubaté, assinado no governo de Afonso Penna 5 .

\footnotetext{
4 VISCARDI, Cláudia Maria Ribeiro. O teatro das oligarquias: uma revisão da "política do café com leite". 2. ed., Belo Horizonte: Fino Traço, 2019. [Ebook].

5 GOMES, Ângela Maria de Castro; FERREIRA, Marieta de Moraes. Primeira República: um balanço historiográfico. Revista Estudos Históricos, Rio de Janeiro, v. 2, n. 4, p. 244-280, dez. 1989. ISSN 2178-1494. Disponível em:
} 


\section{$\underline{\text { hydra }}$}

Em meio a esse ambiente de renovação ocasionado pelos ventos dos anos 1920, estavam os tenentes. O movimento de jovens oficiais do exército brasileiro desejava colocar fim aos vícios que o sistema político republicano vigente possuía até então, tais como o "voto de cabresto". Isso se refletiu na instituição do voto secreto, colocando fim a uma série de mazelas políticas que somente favoreciam as oligarquias e aumentavam ainda mais a corrupção na esfera republicana. Num primeiro momento, esse era um movimento defensor de liberdades democráticas. Os tenentes também olhavam para sua própria categoria ao exigirem melhorias no soldo dos militares.

Já na posse de Arthur Bernardes, provocaram uma crise que levou o presidente eleito a governar praticamente em estado de alerta durante todo o seu mandato. A eclosão do movimento tenentista conhecido como "18 do Forte", em 05 de julho de 1922, visava dar fim ao sistema político vigente e tinha raízes nas instabilidades ocorridas durante o período de indicação de nomes a candidatos, na campanha presidencial de 1921. Para os tenentes, Arthur Bernardes teria escrito cartas ofensivas ao Marechal Hermes da Fonseca e ao exército, e contra ele os tenentes e outras oligarquias insatisfeitas buscaram apoio na candidatura de Nilo Peçanha. Os tenentes foram derrotados nas urnas e também nas armas com o insucesso dos "18 do Forte", assim como em 1924 também foram suprimidos na tentativa de levante contra o governo de São Paulo.

Procurando rever os estudos que até então haviam sido realizados sobre a revolução de 1930, Boris Fausto ${ }^{6}$ entende que o movimento ocorrido naquele ano não necessariamente pode ser pensado como um levante burguês, isto é, não se trata - nos moldes brasileiros - de se pensar uma "revolução burguesa" estruturada nos novos atores urbanos que então

<http://bibliotecadigital.fgv.br/ojs/index.php/reh/article/view/2287/1426>. Acesso em: 19 Abr. 2019.

6 FAUSTO, Boris. A Revolução de 1930 - História e historiografia. 16 ed., São Paulo: Companhia das Letras, 1997. 


\section{hydra}

apareciam no cenário político nacional. Fausto rebate, assim, a tese de que teria ocorrido em 1930 uma aliança contra a oligarquia cafeeira liderada pela burguesia industrial que tomava conta de setores produtivos emergentes. A escolha de Júlio Prestes para ser o candidato de Washington Luís à presidência da república, desfazendo-se a "tradicional" aliança com Minas Gerais para a alternância dos estados federados no poder, levou os setores renovados a apoiarem os candidatos da Aliança Liberal, que tinham à sua frente Getúlio Vargas e João Pessoa.

Para Boris Fausto nada disso teria ocorrido, pois ainda não se pode dizer que em fins dos anos 1920 teríamos no Brasil setores urbanos tão fortes e organizados, capazes de convergirem seus interesses em uma candidatura presidencial que, afinal de contas, poderia ter chegado ao poder, tendo em vista o apoio que receberia, ainda, de oligarquias experientes no jogo político republicano, como seria a oligarquia mineira. A própria participação dessa oligarquia, assim como da oligarquia rio-grandense, leva-nos a pensar que se tratava de um rearranjo de forças no qual estariam se unindo os grupos políticos excluídos, que não conseguiram entrar em um acordo com Washington Luís e Júlio Prestes.

Este artigo, embora tenha de levar em consideração este debate historiográfico, pretende inserir mais um elemento nesta discussão, qual seja, a participação da lgreja no debate político dos anos 1920, especialmente sua participação na campanha eleitoral de 1929-1930. Qual seria o motivo dessa inclusão? Em primeiro lugar, estamos trabalhando com o referencial histórico de reorganização da Igreja no Brasil a partir ainda dos anos 1910, cuja liderança caberia ao arcebispo Dom Sebastião Leme, à frente de importantes arquidioceses do Brasil, entre as quais Pernambuco e Rio de Janeiro. Entendemos que Dom Sebastião Leme arquitetou a reestruturação da Igreja no Brasil que, após a queda do regime imperial, viu-se afastada da política. Importa lembrarmos que no regime imperial a Igreja fazia parte da estrutura 


\section{hydra}

político-administrativa, tendo em vista o sistema de beneplácito e padroado vigente com a constituição de 1824.

A partir da carta-pastoral de Dom Sebastião Leme, datada de 1916, houve um processo de procura, por parte da Igreja, de setores dos quais ela se encontrava afastada até aquele momento. Roberto Romano 7 chama a atenção para a forma como a lgreja se aproximou das lideranças políticas rurais ou urbanas - a partir desse tempo. Por um lado, houve uma aproximação com a própria liderança política, ganhando sua confiança e sendo mais um parceiro na intensa batalha que o campo político produz. Por outro, a ampliação das instituições eclesiásticas, sobretudo o sistema educacional, precisava dos capitais oriundos dessas famílias que controlavam os sistemas políticos regionais.

Na mesma época, houve também uma campanha de reaproximação com o laicato, cujo maior expoente talvez tenha sido Jackson de Figueiredo, fundador do Centro Dom Vital, em 1921, e da revista A Ordem, em 1922. Antes, porém, a Igreja já havia trabalhado na fundação de outra instituição com esses fins, chamada de União dos Moços Católicos. É importante destacarmos a fundação dessas instituições, pois muitas delas atuaram por meio dos inúmeros periódicos que contribuíram para uma reaproximação com o sistema político, numa clara disposição em colaborar. Este seria o caso, por exemplo, da colaboração que Igreja recomendava aos seus (arce)bispos e padres para o recenseamento que o governo federal estaria fazendo em 1922, ano do centenário da independência do Brasil8. Neste mesmo ano, o Vigário Geral da Diocese de Caratinga, Minas Gerais, Monsenhor Aristides Rocha, em uma circular, recomendou ao seu clero que auxiliasse no bom andamento dos trabalhos do recenseamento, tomando, tal como o fizera o bispo de Mariana, de um espírito patriótico para ajudar nessa missão.

\footnotetext{
7 ROMANO, Roberto. Brasil Igreja contra Estado. São Paulo: Kairós, 1979.

8 O DIA. 20 de julho de 1920, p. 1, col. 2. [Setor de Memória da Biblioteca Municipal Murilo Mendes].
} 


\section{hydra}

Até mesmo o campo político veio ao encontro dessa abertura que a Igreja estava dando. Em 1921, o bispo de Mariana, Dom Silvério Gomes Pimenta, viu-se chamado a apoiar os candidatos do Partido Republicano Mineiro (PRM) nas eleições federais realizadas em 1921. Para o deputado Rocha Lagoa Filho, inúmeros boatos estavam sendo espalhados pelo estado, dizendo que o bispo apoiava outro candidato, o que, na sua concepção, era extremamente prejudicial ao desempenho dos candidatos do PRM, devendo Dom Silvério buscar uma solução para que estes não fossem vistos como inimigos do catolicismo?.

Jackson de Figueiredo foi um dos apoiadores da campanha de Arthur Bernardes à presidência da república, já em 1921. Neste caso, cabe ressaltarmos o posicionamento do próprio candidato para que pudesse receber o apoio do clero brasileiro. A imprensa procurava divulgar as cartas de apoio que eram endereçadas a Arthur Bernardes, chamando a atenção para o grande católico que era a despeito de seu possível antagonista, o Marechal Hermes da Fonseca ${ }^{10}$. Bernardes não fez por menos e soube captar o apoio da lgreja, chamando a atenção para a importância da educação católica que recebera e que sempre fez parte da história da educação brasileira, da necessidade de se dar liberdade às escolas para que se ensinasse religião e de seu posicionamento contra o divórcio enquanto deputado federal, quando então um projeto teria sido aventado na Câmara Federall1.

Reside aqui o ponto central de problematização deste artigo: o divórcio, sobre o qual nos permitimos fazer uma pequena analogia. Na campanha presidencial de 2010, a então candidata à presidência, Dilma Rousseff, foi acusada por seu principal antagonista, e opositores em geral, de

9 O DIA. 05 de fevereiro de 1921, p. 1, col. 1-2. [Setor de Memória da Biblioteca Municipal Murilo Mendes].

10 O DIA. 02 de setembro de 1921, p. 1, col. 6. [Setor de Memória da Biblioteca Municipal Murilo Mendes].

11 O DIA. 07 de julho de 1921, p. 1, col. 1-2. [Setor de Memória da Biblioteca Municipal Murilo Mendes]. 


\section{hydra}

se posicionar a favor da instituição do aborto no Brasil. Nos meses que antecederam a eleição, as caixas de correios eletrônicos de inúmeros brasileiros ficaram lotadas de supostas provas a respeito da real intenção da então candidata, caso viesse a assumir a presidência da república. O debate ganhou contornos religiosos fortes, com católicos e (neo)pentecostais possivelmente unidos na intenção de provar a todo eleitorado brasileiro que a vitória de Dilma seria a derrota da família brasileira. Ao iniciar sua campanha ao segundo turno, Dilma foi aos órgãos de comunicação negar todas as acusações e qualquer convicção que porventura tivesse em relação ao aborto $^{12}$.

Com esse exemplo, queremos mostrar que esta discussão não é necessariamente nova nas campanhas presidenciais no Brasil. O elemento religioso fez e ainda fará parte das campanhas presidenciais - e para outros cargos políticos no Brasil - ainda por muito tempo. Este é um debate importante, pois incide diretamente sobre a autonomia que homens e mulheres têm para decidirem qual modelo de família gostariam de manter. Neste sentido, a família é vista como algo sagrado, sob o qual o poder público não pode ingerir. Ao atuar sobre a política, a Igreja procura evitar a dessacralização da família, algo que positivistas e liberais têm intentado desde os tempos imperiais, atuando sobre a escola, a assistência e sobre a própria família $^{13}$. Vale notarmos como o debate em torno do divórcio no Brasil se arrastou durante décadas, tendo sido aprovado somente nos anos 1970, durante a ditadura civil-militar.

É interessante destacarmos que, em meio aos debates relativos ao modelo econômico que o Brasil deveria assumir com a vitória do candidato à

\footnotetext{
12 LUNA, Naara. A controvérsia do aborto e a imprensa na campanha eleitoral de 2010. Caderno CRH, Salvador, v. 27, n. 71, p. 367-391, ago. 2014. Disponível em: <http://dx.doi.org/10.1590/S0103-49792014000200010>. Acesso em: 19 abr. 2019.

13 PINTO, Jefferson de Almeida. Os lazaristas e a política imperial - uma escola, uma assistência e a família. Topoi, Rio de Janeiro, v. 17, n. 32, p. 153-175, jun. 2016. Disponível em: <https://www.scielo.br/pdf/topoi/v17n32/2237-101X-topoi-17-32-00153.pdf>. Acesso em: 29 jun. 2020.
} 


\section{hydra}

presidência da república para o período de 1930-1934, o debate religioso também se fez presente. Júlio Prestes foi acusado de não estar de acordo com os sentimentos da família brasileira, e muitos órgãos de imprensa, unidos às lideranças religiosas do país, posicionaram-se contra o então governador de São Paulo. A sua possível eleição era vista como uma perspectiva de calamidade, posto que a bancada do Partido Republicano Paulista (PRP), com a anuência do então presidenciável, teria apresentado um projeto de "divórcio a vínculo" no Congresso Nacional que dizia fazer parte da plataforma eleitoral de Júlio Prestes. Embora não seja possível dizer qual era o posicionamento de Getúlio Vargas sobre o assunto, é notório que o apoio que Ihe era dado por Antônio Carlos Ribeiro de Andrada o legitimava frente aos interesses da Igreja ${ }^{14}$. Isto porque, embora vestisse o cândido manto do liberalismo, Antônio Carlos buscava sempre dar vazão aos anseios romanos, como seria o caso do retorno do ensino religioso nas escolas mineiras enquanto foi presidente do Estado de Minas Gerais (1927-1930) ${ }^{15}$.

Fato é que no primeiro governo Vargas (1930-1934), quando Francisco Campos esteve à frente do Ministério da Educação e Saúde, a faculdade em relação ao ensino religioso nas escolas públicas passou a vigorar. Francisco Campos já havia sido Secretário do Interior de Antônio Carlos, quando presidente de Minas Gerais e, portanto, já havia encabeçado as reformas educacionais que mais tarde estendeu a todo o país. Voltando a Dom Sebastião Leme, é interessante ressaltarmos a pressão que fizera sobre o então presidente Washington Luís para que deixasse vaga a presidência da República, quando então já havia estourado o movimento revolucionário liderado por Getúlio Vargas no Sul em direção ao Rio de Janeiro.

\footnotetext{
14 DIÁRIO MERCANTIL. 16 de setembro de 1929, p. 1, col. 1-2. [Arquivo Histórico da Cidade de Juiz de Fora].

15 DIÁRIO MERCANTIL. 1 de novembro de 1928, p. 1, col. 1-2. [Arquivo Histórico da Cidade de Juiz de Fora]. Antônio Carlos também criaria o cargo de capelão da Força Pública de Minas Gerais. Cf. A EGREJA e o Estado. Diário Mercantil, 12 de setembro de 1928, p. 1, col. 1-2. [Setor de Memória da Biblioteca Municipal Murilo Mendes].
} 


\section{hydra}

\section{Material e métodos}

É possível identificarmos uma enorme produção de textos e livros sobre a temática datados de meados da década de 1930 em diante, mas, ao nos debruçarmos sobre sua leitura, podemos notar uma filiação muito próxima da Igreja. Isso pode ser explicado em função do movimento de formação da neocristandade brasileira encampado por Dom Sebastião Leme, que, entre suas várias nuances, buscava reaproximar a Igreja dos intelectuais que, no século XIX, haviam se afastado dos altares ${ }^{16}$. Assim sendo, muitos dos homens que escreveram sobre a história da Igreja no Brasil, ao longo do século XX, assim o fizeram como uma forma de mostrar a grandeza da instituição e sua importância para a configuração do Brasil enquanto estado nação 17. Cabe atentarmos também para o fato de ter sido a partir do governo de Getúlio Vargas a reaproximação oficial da Igreja com o Estado no Brasill8.

Paralelamente, escrever sobre a Igreja também foi objeto da academia. Muitos estudos historiográficos, utilizando-se de documentos e métodos pertinentes à escrita da história, revelam uma ampla produção sobre a presença da Igreja no Brasil, sobretudo na perspectiva da história cultural. Entre estes é significativo como os historiadores procuram estudar a presença da Companhia de Jesus e seu papel no processo de colonização e catequização/conversão do gentio no continente americano ${ }^{19}$. A produção historiográfica também tem se utilizado da documentação produzida pela

${ }_{16}$ Cf. MAINWARING, Scott. Igreja Católica e política no Brasil (1916-1985). São Paulo: Brasiliense, 2004, p. 41.

17 SILVA, Ana Paula Barcelos Ribeiro da. Diálogos sobre a escrita da história. Brasil e Argentina (1910-1940). Ibero-americanismo, catolicismo, cooperação intelectual, (des)qualificação e alteridade. Brasília: Fundação Alexandre de Gusmão, 2011 , p. 178.

18 AZZI, Riolando; GRIJP, Klaus van der. História da Igreja no Brasil: ensaio de interpretação a partir do povo. Terceira Época. Petrópolis: Vozes, 2008, p. 223-224.

${ }_{19}$ Cf. GOMES, Francisco José da Silva. Quatro séculos de cristandade no Brasil. In: Seminário Internacional de História das Religiões. Associação Brasileira de História das Religiões, Recife. Anais... Recife, 2001. (digitado); AZZI, Riolando. Os primórdios da catequese: arranjos do período colonial e imperial. In: PASSOS, Mauro (Org.). Uma história no plural: 500 anos do movimento catequético brasileiro. Petrópolis: Vozes, 1999. 


\section{hydra}

Igreja como fonte para trabalhos na área da história social, em estudos que revelam a face da sociedade escravista e suas práticas de devoção e piedade, o papel das irmandades leigas, entre outros 20 .

Pensar a cultura religiosa e suas relações com o campo político também tem sido objeto de estudo para outros historiadores, cientistas políticos, advogados, entre outros, que procuram destacar o papel da cultura religiosa em várias esferas da vida política na passagem à modernidade. Muitos desses estudos têm buscado dialogar com as tensões provocadas pelas reformas pombalinas no seio da Igreja romana, tocada com o advento iluminista desde o século XVIII21. Neste sentido, deparamo-nos com uma lgreja que necessita dialogar com a modernidade e precisa estar politicamente articulada para resistir às ondas secularizantes que então tomaram as instituições do Antigo Regime, no intuito de derrubá-las.

É relevante nesta discussão os estudos teóricos desenvolvidos por Pierre Bourdieu sobre a dissolução do campo religioso. Bourdieu entende que há um conjunto de pessoas capazes de trazer à tona uma discussão que interessa à sociedade e que a permite romper com o campo religioso então dominante. Essas pessoas podem ser aqui entendidas como um conjunto de profissionais

20 VENÂNCIO, Renato Pinto. Famílias abandonadas: assistência à criança de camadas populares no Rio de Janeiro e em Salvador - séculos XVIII e XIX. Campinas: Papirus, 1999; FIGUEIREDO, Luciano Raposo de Almeida. Barrocas Famílias: a vida familiar em Minas Gerais no século XVIII. São Paulo: Hucitec, 1997.

${ }^{21}$ Cf. NEDER, Gizlene; CERQUEIRA FILHO, Gisálio. Idéias jurídicas e autoridade na família. Rio de Janeiro: Revan, 2007. Cf. dissertações e teses orientadas por Gizlene Neder que trabalham na perspectiva das relações entre a cultura política, jurídica e religiosa: GALANTE, Rachel de Souza. O punhal da fé: idéias políticas, jurídicas e religiosas sobre o casamento civil no Segundo Reinado. Niterói, 2008. Dissertação (Mestrado em História) - Instituto de Ciências Humanas e Filosofia, Universidade Federal Fluminense, Niterói. 2008; RAMOS, Henrique César Monteiro Barahona. A revista $O$ Direito - periodismo jurídico e política no final do Império do Brazil. Niterói, 2009. Dissertação (Mestrado em Sociologia e Direito) - Instituto de Ciências Humanas e Filosofia, Universidade Federal Fluminense, Niterói. 2009.; RODRIGUES, Fabiana Cardoso Malha. Idéias jurídicas famílias e filiação na passagem à modernidade no Brasil, 18901940. Niterói, 2008. Tese (Doutorado em História) - Instituto de Ciências Humanas e Filosofia, Universidade Federal Fluminense, Niterói. 2008. 287 págs. Cf. tb. BORRMANN, Ricardo Gaulia. Tal mercado, tal príncipe: o paradigma da perfeição na economia política burguesa. Niterói, 2009. Dissertação (Mestrado em Ciência Política) - Instituto de Ciências Humanas e Filosofia, Universidade Federal Fluminense, Niterói. 2009, orientado por Gisálio Cerqueira Filho, que dirige os Seminários Internos de Pesquisa do Laboratório Cidade e Poder. 


\section{hydra}

capazes de pensar e agir cientificamente sobre a vida das pessoas, portanto, trazer-Ihes respostas e pensar alternativas às limitações que o campo religioso então Ihes impunha. Tem-se a noção de que corpo e alma não são mais a mesma coisa, o que parece ser pertinente quando pensamos a necessidade da secularização no século XIX22.

É neste ambiente que podemos inserir a discussão sobre a família, cujos estudos têm revelado o seu entendimento sobre a perspectiva cristã. Diz François Lebrun que, para exercer o controle sobre a família, a Igreja instituiu o casamento, pensando-o como um sacramento e cujo fim último seria a procriação. Tal visão se chocava diretamente com $\circ$ que diziam os protestantes, como seria o caso de João Calvino, que via o sexo como uma dádiva divinal, devendo-se fazer uso dele com fins de alegria, sem que fossem gerados filhos dos quais o casal não pudesse cuidar ${ }^{23}$. Nesse processo de intervenção da Igreja na família, diz Lebrun que a instrução seria um dos deveres que os pais teriam para com os filhos, entretanto, seria preciso instruir dentro do catolicismo. Neste sentido, faria jus a intervenção da Igreja na própria escola, que não deveria nunca ser laicizada24.

Tomando esses estudos por referência, procuramos fazer uma análise de conteúdo a partir do que foi produzido na imprensa brasileira e que toca a campanha presidencial de 1929-1930. O ponto de partida para a execução deste estudo foi a recuperação da trajetória política de Júlio Prestes nos anos que antecederam sua candidatura à presidência da República. É importante destacarmos, nesse cenário, a formação da memória de Júlio Prestes no contexto brasileiro. Como sabemos, a Revolução de 1930 provocou seu exílio

22 BOURDIEU, Pierre. A dissolução do religioso. In: BOURDIEU, Pierre. Coisas Ditas. Rio de Janeiro: Brasiliense, 1990, p. 122.

23 LEBRUN, François. O sacerdote, o príncipe e a família. Lisboa: Terramar, s/d, p. 84-87.

24 LEBRUN, François. O sacerdote, o príncipe e a família. Lisboa: Terramar, s/d, p. 91. Estamos também nos baseando em HESPANHA, Antônio Manuel. Carne de uma só carne: para uma compreensão dos fundamentos histórico-antropológicos da família na época moderna. Análise social - Revista do ISCTE, Lisboa, n. 123-124, v. XXVIII, 1993. 


\section{hydra}

até 1934 na Inglaterra. Esse processo fez com que, fora de São Paulo, poucos conhecessem sua imagem, sua trajetória e sua memória política.

A análise documental também incidiu sobre uma série de artigos publicados na imprensa brasileira nos anos 1920, que demonstram como a Igreja estaria se rearticulando frente à necessidade de se adaptar aos tempos republicanos. A partir dessa documentação, percebemos como a questão dos direitos civis afetavam diretamente a organização familiar e estavam sendo o alvo dessa instituição. Esta documentação apresenta indícios muitos fortes da necessidade da Igreja de colocar no poder políticos católicos que passassem a fazer uma política da Igreja. Esta política passaria pela indissolubilidade do vínculo matrimonial - que já estava na sua pauta desde as discussões do Código Civil - até a volta do ensino religioso às escolas públicas brasileiras.

São sintomáticos, deste modo, os ataques àqueles políticos que não estariam na base da Igreja e, isto aponta para a trajetória política de Júlio Prestes. Por isso, tomamos como objeto notícias publicadas em alguns jornais sobre a campanha presidencial de 1929-1930. Este levantamento deu-se a partir do Jornal do Commercio que chegava tanto aos setores populares quanto aos setores políticos. Assim também, encontramos referências no Correio da Manhã, no Diário Carioca, em Crítica, A Gazeta e o Diário Nacional.

\section{Resultados e discussão}

Júlio Prestes de Albuquerque nasceu em 15 de março de 1882, em Itapetininga, São Paulo, crescendo nos últimos anos do governo monárquico e presenciando o surgimento da República e a forte influência das elites oligárquicas na política. Seu pai Fernando Prestes de Albuquerque foi presidente do Estado de São Paulo entre 1898-1900, durante o governo Campos Sales. Entre 1902-1906 Prestes cursou a Faculdade de Direito de São 


\section{$\underline{\text { hydra }}$}

Paulo, instituição que formou diversos políticos, juristas e escritores que tiveram participação na trajetória histórica da República. Enquanto cursava a faculdade, também participou de grupos literários, chegando a fundar um periódico em conjunto com colegas de Direito chamado A Musa. A admiração pela literatura já vinha desde sua adolescência, quando publicava poemas em jornais no interior de São Paulo. Ele escreveu até o fim de sua vida acerca de diversos temas, incluindo discursos políticos.

Após o bacharelado em Direito, montou um escritório de advocacia e passou a se dedicar unicamente a essa profissão, até que, em 1909, começou a dividir esse ofício com a atividade parlamentar, iniciando sua trajetória política quando eleito deputado estadual em São Paulo pelo Partido Republicano Paulista (PRP), exercendo essa função no Congresso Legislativo até 1923. Entre 1924 a 1927, foi deputado na Câmara Federal. Com a morte de Carlos de Campos, foi eleito presidente do Estado de São Paulo25.

No decorrer de 1909 a 1923, Júlio Prestes propôs projetos e emendas sobre questões econômicas, como a divisão física de propriedades rurais, a seguridade social, aumento nos vencimentos dos funcionários públicos, além da criação de tribunais rurais para amenizar os conflitos entre proprietários rurais e colonos. Durante a gestão de Washington Luís como presidente do Estado de São Paulo (1920-1924), foi eleito líder de governo. Já em seu governo adotou diversas medidas como a busca pelo petróleo, a criação de escolas profissionalizantes mistas e a priorização do café26.

A ativa trajetória política de Prestes resultou em sua indicação como presidenciável em 1929, sendo apoiado pelo então presidente Washington Luís. As eleições ocorreram em março de 1930 tendo sido eleito presidente. Ainda não empossado, começaram a surgir movimentos de contestação ao

25 FUNDO BR SPAPESP JPA - Júlio Prestes de Albuquerque. Arquivo Público do Estado de São Paulo, São Paulo, 2016. Disponível em: <http://icaatom.arquivoestado.sp.gov.br/icaatom/index.php/julio-prestes-2;isad>. Acesso em: 20 abr. 2020.

${ }_{26}$ FUNDO BR SPAPESP JPA - Júlio Prestes de Albuquerque. Arquivo Público do Estado de São Paulo, São Paulo, 2016. Disponível em: <http://icaatom.arquivoestado.sp.gov.br/icaatom/index.php/julio-prestes-2;isad>. Acesso em: 20 abr. 2020. 


\section{hydra}

resultado da eleição, com os partidários de Getúlio Vargas inconformados com os resultados e com a repentina morte de João Pessoa. Além disso, os tenentes estavam insatisfeitos com as regras eleitorais vigentes e a Igreja Católica movimentava-se buscando obter maior participação nas decisões governamentais no que diz respeito à instituição familiar. Esses setores provocaram uma intensa movimentação política que culminou na chamada Revolução de 1930 e no exílio político de Júlio Prestes por quatro anos ${ }^{27}$.

Mas foi durante a campanha presidencial iniciada em 1929 que um tema também ganhou relevo nas discussões políticas: o divórcio a vínculo. Essa discussão teve como base um projeto de lei proposto pelo advogado e senador Celso Bayma. 28 O tema já se arrastava pelos setores políticos brasileiros desde a instituição do casamento civil em 1890 passando pelo projeto e aprovação do Código Civil de 1916 que não resolveu o caso. Ao longo das primeiras décadas do século XX situações diversas entre as famílias apareciam, uma vez que o Código Civil permitia a separação de corpos, isto é, o desquite. Mulheres e imigrantes, por exemplo, reivindicavam o direito ao divórcio a fim de reconstruírem suas vidas já que um primeiro casamento não Ihes havia trago a felicidade como seriam os vários casos de adultério. Dizia Bayma: "Admito, por exemplo, que se rompam os laços conjugais somente para o cônjuge inocente, de inocência ressaltante em sentença de desquite passada em julgado, e isso depois de dois ou três anos, para se afastar a hipótese de suborno, coação, etc." 29.

${ }^{27}$ FUNDO BR SPAPESP JPA - Júlio Prestes de Albuquerque. Arquivo Público do Estado de São Paulo, São Paulo, 2016. Disponível em: <http://icaatom.arquivoestado.sp.gov.br/icaatom/index.php/julio-prestes-2;isad>. Acesso em: 20 abr. 2020.

28 DIÁRIO CARIOCA. 27 de maio de 1929, p. 1, col. 3. [Acervo da Biblioteca Nacional]. Disponível <http://memoria.bn.br/docreader/093092 01/3100?pesq=divorcio\%20a\%20vinculo>. Acesso em: 20 abr. 2020.

29 DIÁRIO CARIOCA, 27 de maio de 1929, p. 1, col. 3. [Acervo da Biblioteca Nacional]. Disponível em: <http://memoria.bn.br/docreader/093092 01/3100?pesq=divorcio\%20a\%20vinculo>. Acesso em: 20 abr. 2020. 


\section{hydra}

No setor político, havia divergências de opiniões em relação a alterações no Código Civil. O próprio Partido Republicano Paulista estava dividido em opiniões entre aqueles que se diziam favoráveis aos valores da família e os que viam o divórcio como facilitador das relações sociais ${ }^{30}$. No entanto, em junho de 1929, o projeto de lei de Celso Bayma foi interrompido, uma vez que o então presidente Washington Luís manifestava-se contra o divórcio a vínculo31. "O senador Celso Bayma engoliu o projeto da Lei do Divórcio [...] para não ir de encontro aos desejos do sr. Washington Luís, que se mostrou contrário ao divórcio a vínculo em nosso país." 32.

Isso não impediu, entretanto, que o debate estivesse presente na campanha presidencial e na representação popular acerca dos presidenciáveis. Para estes, a questão de serem ou não católicos se tornou algo decisivo. Getúlio Vargas foi colocado e defendido como o candidato dos católicos, maioria da população brasileira e certamente dos aptos a votar dando início a uma disputa de narrativas na imprensa: "(...) o dr. Getúlio Vargas é o candidato dos catholicos, que são a maioria, e o dr. Júlio Prestes, que sempre tem feito ostentação de ser infenso ao catholicismo, é o candidato dos protestantes, que são uma ridícula minoria!" 33.

O Diário Carioca, criado em 1928, manifestava-se como um jornal de oposição ao governo de Washington Luís demonstrando vigoroso apoio a Getúlio Vargas, frequentemente apresentando notícias e argumentos que desfavoreciam a campanha de Prestes. Em suas páginas, Prestes era acusado

\footnotetext{
30 A REPÚBLICA: Orgam do Partido Republicano. 29 de maio de 1929, p. 1, col. 1. [Acervo da Biblioteca Nacional]. Disponível em: <http://memoria.bn.br/DocReader/215554/38694?.pesq=divorcio >. Acesso em: 20 abr. 2020.

${ }^{31}$ O DIA. 28 de junho de 1929, p. 2, col. 2. [Acervo da Biblioteca Nacional]. Disponível em: $<$ http://memoria.bn.br/DocReader/092932/15148?pesq=celso\%20bayma>. Acesso em: 20 abr. 2020.

32 O DIA. 28 de junho de 1929, p. 2, col. 2. [Acervo da Biblioteca Nacional]. Disponível em: <http://memoria.bn.br/DocReader/092932/15148?pesq=celso\%20bayma>. Acesso em: 20 abr. 2020.

${ }^{33}$ DIÁRIO CARIOCA. Rio de Janeiro, 19 de outubro de 1929, p. 4, col. 2. [Acervo da Biblioteca Nacional].

Disponível em: <http://memoria.bn.br/DocReader/093092 01/4283?pesq=Getulio\%20Vargas\%20católico>. Acesso em: 20 abr. 2020.
} 


\section{hydra}

de defender o protestantismo sendo representado de forma pejorativa ainda por outros jornais, gerando um descrédito do candidato com a sociedade majoritariamente católica, bem como com o próprio clero 34: "(...) sendo catholica a maior parte da Nação, isto é, a grande maioria dos brasileiros, estes devem votar no dr. Getúlio Vargas e não no candidato do insignificante numero dos protestantes (...)" 35.

A acusação permitiu que setores da Igreja como o Centro Popular Mineiro, uma associação de eleitores católicos, se posicionasse a favor de Getúlio Vargas por este ter sempre se declarado católico e contra o divórcio, enquanto Júlio Prestes era considerado não católico ou protestante, apresentando uma imagem negativa a esse setor. Ademais, afirmava que Prestes havia se colocado contra as emendas católicas, principalmente 0 ensino religioso e obras em propriedades mantidas pela Igreja, tais quais catedrais, orfanatos e hospitais:

O sr. Júlio Prestes, na Camara Federal, em aparte a um discurso do deputado Azevedo Lima, pronunciou essa phrase que não pode deixar de contraindical-o aos catholicos: 'O sr. presidente da Republica queria as emendas religiosas, mas nós as derrubamos aqui na Camara'. ${ }^{36}$

Foi também afirmado que pretendia que o divórcio fosse concebido, demonstrando que o eleitorado não devia votá-lo: "O sr. Getúlio Vargas é

\footnotetext{
${ }^{34}$ DIÁRIO CARIOCA. Rio de Janeiro, 19 de outubro de 1929, p. 4, col. 2. [Acervo da Biblioteca Nacional]. Disponível em: <http://memoria.bn.br/DocReader/093092_01/4283?pesq=Getulio\%20Vargas\%20católico>. Acesso em: 20 abr. 2020.

35 DIÁRIO CARIOCA. Rio de Janeiro, 19 de outubro de 1929, p. 4, col. 2. [Acervo da Biblioteca Nacional]. <http://memoria.bn.br/DocReader/093092 01/4283?.pesq=Getulio\%20Vargas\%20católico>. Acesso em: 20 abr. 2020.

36 DIÁRIO CARIOCA. Rio de Janeiro, 22 de Setembro de 1929, p. 2, col. 5. [Acervo da Biblioteca Nacional]. <http://memoria.bn.br/DocReader/093092 01/4033?pesq=\%22divorcio\%20Julio\%20Prestes\%2 2>. Acesso em: 20 abr. 2020.
} 


\section{hydra}

contra o divórcio e o sr. Júlio Prestes o deseja." 37. Deste modo, evidencia-se que a Igreja Católica buscava influenciar na esfera política para alcançar seus objetivos, como estabelecer o ensino religioso de vertente católica nas escolas, o financiamento por parte do Estado de obras mantidas pela Igreja e a indissolubilidade do casamento.

Assim, com a divulgação das ideias religiosas dos presidenciáveis, descritas pelo jornal Diário Carioca, o assunto também era debatido por outros órgãos de imprensa como o Correio da Manhã apresentando outra visão sobre os candidatos e sobre a cobertura da eleição. "Ao mesmo tempo, recebemos informações positivas de que a Imprensa Official de Minas está imprimindo e fazendo distribuir em larga escala cartazes insinuando que o eminente sr. Júlio Prestes é contrário ao catholicismo" 38. O jornal ainda afirmava que alguns desses cartazes estavam situados nas portas de igrejas católicas, contrariando a lógica do regime vigente, no qual deveria predominar a liberdade espiritual. Entretanto, o periódico se volta para a narrativa de que Júlio Prestes seria católico, ao contrário do que era divulgado, objetando o Diário Carioca ${ }^{39}$.

O sr. Júlio Prestes é católico. Pertence a uma família tradicionalmente católica. Educou todos os seus filhos em colégios católicos. Foi, durante seis anos, fiscal de um colégio católico (...) onde conviveu com os jesuítas que o dirigem e que

\footnotetext{
37 DIÁRIO CARIOCA. Rio de Janeiro, 22 de Setembro de 1929, p. 2, col. 5. [Acervo da Biblioteca Nacional]. Disponível em: <http://memoria.bn.br/DocReader/093092_01/4033?pesq=\%22divorcio\%20Julio\%20Prestes\%2 2>. Acesso em: 20 abr. 2020.

38 CORREIO DA MANHÃ. Rio de Janeiro, 11 de outubro de 1929, p. 3, col. 3. [Acervo da Biblioteca Nacional]. Disponível em: $<$ http://memoria.bn.br/DocReader/089842 03/42536?pesq=os\%20sacrilégios\%20do\%20liberali smo>. Acesso em: 20 abr. 2020.

${ }^{39}$ CORREIO DA MANHÃ. Rio de Janeiro, 11 de outubro de 1929, p. 3, col. 3. [Acervo da Biblioteca Nacional].

Disponível em: $<$ http://memoria.bn.br/DocReader/089842 03/42536?pesq=os\%20sacrilégios\%20do\%20liberali smo>. Acesso em: 20 abr. 2020.
} 


\section{hydra}

poderão atestar as suas firmes, arraigadas e sinceras convicções religiosas. 40

O periódico Crítica (RJ) asseverava que Antônio Carlos, o então presidente de Minas Gerais era o responsável pela divulgação de cartazes contra a reputação de Júlio Prestes. Dizia em suas páginas que o mesmo era um "cretino" que perturbava a ordem pública e desrespeitava igrejas e sacerdotes, ao ir contra as suas ordens de não distribuir e colar cartazes em frente a igrejas ${ }^{41}$.

Nessa conjuntura, o jornal A Gazeta (SP) também fez ponderações em relação às condutas de Antônio Carlos que, apesar de afirmar ser "catholico fervoroso", apresentou um projeto autorizando o ensino religioso nas escolas, mas de forma que abrangesse várias religiões. Com isso, despertou um clima insatisfatório, acarretando outras dúvidas que foram consideradas atestadoras de seu possível anticatolicismo. Entre estas, sua cooperação com a Aliança Liberal, da qual participou para apoiar a candidatura de Getúlio Vargas, em que o Estado de Minas Gerais não teria compatibilidade moral com o estado do Rio Grande do Sul, pois este seguia a doutrina positivista. Logo, o país seria guiado pelos ideais positivistas como seria do conhecimento de Antônio Carlos Ribeiro de Andrada 42.

No entanto, compreende-se que o jornal buscava desmoralizar a campanha do presidente de Minas Gerais, contestando o seu catolicismo para demonstrar que realmente quem seguia a conduta católica era Júlio

40 CORREIO DA MANHÃ. Rio de Janeiro, 11 de outubro de 1929, p. 3, col. 3. [Acervo da Biblioteca Nacional].

Disponível

em: <http://memoria.bn.br/DocReader/089842 03/42536?.pesq=0s\%20sacrilégios\%20do\%20liberali smo>. Acesso em: 20 abr. 2020.

${ }^{41}$ CRítICA. Rio de Janeiro, 13 de outubro de 1929, p. 3, col. 3. [Acervo da Biblioteca Nacional]. Disponível em: <http://memoria.bn.br/DocReader/372382/2110?pesq=julio\%20prestes>. Acesso em: 20 abr. 2020.

42 A GAZETA. São Paulo, 21 de Dezembro de 1929, p. 1, col. 2. [Acervo da Biblioteca Nacional]. Disponível em: <http://memoria.bn.br/DocReader/763900/30826?pesq=ensino\%20religioso\%20julio\%20preste s>. Acesso em: 20 abr. 2020. 


\section{hydra}

Prestes, como forma de manifestar partidarismo para a sua candidatura. Não obstante, o mesmo jornal fez questão de salientar que o presidente do estado de São Paulo era católico e seguia a moral e os costumes da religião, apresentando uma fotografia em que estão Júlio Prestes e sua família na Igreja da Candelária no Rio de Janeiro43.

Figura 1 - "O Sr Júlio Prestes é bom catholico. Ei-o aqui, em companhia de sua exma. família, assistindo uma missa, [...]."

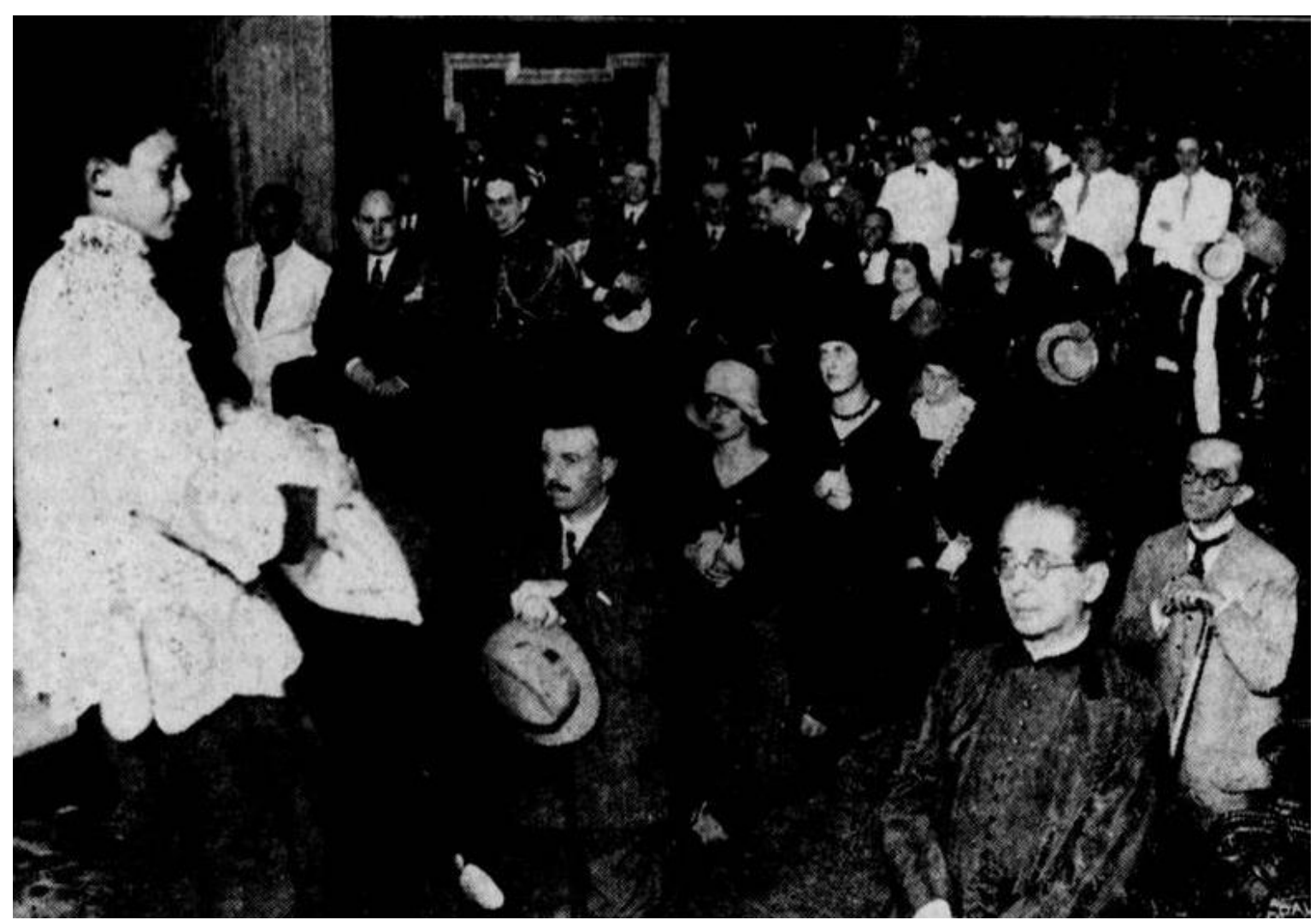

Fonte: A GAZETA. São Paulo, 21 de Dezembro de 1929, p. 1, col. 2. [Acervo da biblioteca Nacional]. Disponível em:

http://memoria.bn.br/DocReader/763900/30826?pesq=ensino\%20religioso\%20julio\%20prestes >. Acesso em: 20 abr. 2020.

${ }^{43}$ A GAZETA. São Paulo, 21 de Dezembro de 1929, p. 1, col. 2. [Acervo da Biblioteca Nacional]. Disponível em: $<$ http://memoria.bn.br/DocReader/763900/30826?pesq=ensino\%20religioso\%20julio\%20preste s>. Acesso em: 20 abr. 2020. 


\section{hydra}

Entretanto, mesmo com diversas declarações sobre o catolicismo de Júlio Prestes, o debate sobre a religião dos candidatos ainda era discutido em múltiplos setores da sociedade. Exemplo disso é a carta de João Calunga na gazeta Diário Nacional: A Democracia em Marcha (SP), na qual apresenta uma refutação a um homem de São Vicente. Este afirmou para o matutino que as mães católicas deveriam convencer seus filhos a votarem em Júlio Prestes, pois ele poderia salvar a religião.

Em resposta, João Calunga alega que havia uma acusação na qual Júlio Prestes teria entrado em um templo para desacatar e ofender o senhor cardeal metropolitano. Além de ter sido qualificado de prestar subordinação aos protestantes dos Estados Unidos, como o caso das centrais elétricas que passaram a pertencer aos norte-americanos, afirmando que não prestou nenhum tipo de resistência a "invasão" pelos protestantes: "[...] o situacionismo brasileiro, dos srs. Prestes, Washington, etc., presta inteira obediência aos protestantes de Wall Street" 44.

Em consequência desses fatos, João Calunga aconselha o homem de Santos e aos católicos a votarem em Getúlio Vargas, para não impulsionarem o protestantismo: "O homem de São Vicente, não deve aconselhar ninguém a votar na política situacionista, pois assim dará força aos protestantes. Se é católico, faça como eu, que votarei em Getúlio Vargas e João Pessoa." 45. O mesmo periódico em matéria nomeada "O Sr. Júlio Prestes é contra o Catolicismo", o presidenciável teria solicitado ao prefeito do Rio de Janeiro que vetasse o auxílio monetário para as obras do monumento do Cristo

44 DIÁRIO NACIONAL: A Democracia em Marcha. São Paulo, 17 de Outubro de 1929, p. 8, col. 3. [Acervo da Biblioteca Nacional]. Disponível em: <http://memoria.bn.br/docreader/213829/7950?.pesq=\%22Julio\%20Prestes\%20>. Acesso em: 20 abr. 2020.

45 DIÁRIO NACIONAL: A Democracia em Marcha. São Paulo, 17 de Outubro de 1929, p. 8, col. 3. [Acervo da Biblioteca Nacional]. Disponível em: <http://memoria.bn.br/docreader/213829/7950?pesq=\%22Julio\%20Prestes\%20>. Acesso em: 20 abr. 2020. 


\section{hydra}

Redentor, uma vez que, por ser contra a religião católica, ele era contra a realização dessa construção ${ }^{46}$.

A partir de tantas declarações que associavam Júlio Prestes ao não catolicismo ou ao protestantismo, o bispo Francisco de Campos Barreto, da diocese de Campinas, faz uma declaração sobre o presidenciável no periódico Correio Paulistano.

[...] só tenho motivos para congratular-me com o sr. Júlio Prestes, que [...] declarando-se católico, entoou um hino de louvor aos católicos [...]. Por isso, não compreendo que haja católicos que combatam um candidato que 'reconhecendo os serviços sociais prestado pela Igreja, ainda the atribui austeridade dos costumes, dentro dos quais se organiza a família brasileira, protegendo-a contra a dissolução e o desregramento que tem comprometido as organizações de outros países. ${ }^{47}$

Após a declaração do bispo o jornal afirmou que Júlio Prestes era um ilustre candidato à presidência da República ${ }^{48}$. Assim, há extensas diferenças de opiniões sobre a candidatura de Júlio Prestes durante os anos de 1929 e 1930. Observam-se acusações em viés religioso, com o intuito de dificultar a candidatura do presidenciável, apresentando Getúlio Vargas como o principal candidato para suprir as necessidades da família católica brasileira e manter os valores cristãos, afastando Prestes desse cenário.

46 DIÁRIO NACIONAL: A Democracia em Marcha. São Paulo, 17 de Outubro de 1929, p. 8, col. 3. [Acervo da Biblioteca Nacional]. Disponível em: <http://memoria.bn.br/docreader/213829/7950?.pesq=\%22Julio\%20Prestes\%20>. Acesso em: 20 abr. 2020.

47 CORREIO PAULISTANO. São Paulo, 28 de dezembro de 1929, p. 5, col. 3. [Acervo da Biblioteca Nacional]. Disponível em: <http://memoria.bn.br/DocReader/090972 07/39339?pesq=Julio\%20Prestes\%20igreja>. Acesso em: 20 abr. 2020.

48 CORREIO PAULISTANO. São Paulo, 28 de dezembro de 1929, p. 5, col. 3. [Acervo da 


\section{hydra}

\section{Conclusões}

O tema do divórcio sempre foi pautado na imprensa tendo ganhado maior destaque com a proposta feita por Celso Bayma de legaliza-lo. Naquele contexto, a Igreja sempre expôs sua insatisfação com essa discussão, alegando que o projeto seria contra a religião e a família. Assim, durante a campanha presidencial de 1929-1930 o tema foi uma das principais pautas de discussão, percebendo-se a forte influência da religião e da Igreja nos debates acerca das propostas dos presidenciáveis em relação a família. Assim, o que transparece já nas décadas de 1920 e 30 são os resultados do processo de recristianização a que a mesma encampou ao longo da primeira República recolocando-se no cenário político ao qual havia sido excluída com o fim do padroado.

Nessa conjuntura, podemos constatar que o fato de Júlio Prestes supostamente não atender aos anseios da lgreja, principalmente por não se manifestar contra o divórcio sendo constantemente associado também ao protestantismo, trouxe um posicionamento reticente do clero e do laicato em relação a sua candidatura e futuro governo. Já Getúlio Vargas era o candidato associado aos católicos. Essa assertiva nos leva a refletir sobre algumas ações tomadas em seu governo pensando-as também como hipótese para estudos futuros. Neste sentido, levantamos aqui no Decreto $n^{\circ}$ 19.941, de 30 de Abril de 1931, que tratava da instrução religiosa nos ensinos primário, secundário e normal. Além disso, a atuação da própria Igreja na política refutando a fundação de um partido católico, mas garantindo apoio a todos aqueles que se posicionassem a favor das pautas cristãs o que nos leva ao contexto em que se deu a formação da Assembleia Nacional Constituinte de 1934 e a discussão que garantiu a indissolubilidade do casamento pelos seus parlamentares. 


\section{hydra}

\section{REFERÊNCIAS}

A EGREJA e o Estado. Diário Mercantil, 12 de setembro de 1928, p. 1, col. 1-2. [Setor de Memória da Biblioteca Municipal Murilo Mendes].

A GAZETA. São Paulo, 21 de Dezembro de 1929, p. 1, col. 2. [Acervo da Biblioteca Nacional].

Disponível

em:

<http://memoria.bn.br/DocReader/763900/30826?pesq=ensino\%20religioso\%20julio\% 20prestes>. Acesso em: 20 abr. 2020.

A REPÚBLICA: Orgam do Partido Republicano. 29 de maio de 1929, p. 1, col. 1. [Acervo da Biblioteca Nacional]. Disponível em: <http://memoria.bn.br/DocReader/215554/38694?pesq=divorcio>. Acesso em: 20 abr. 2020.

AZZI, Riolando. Os primórdios da catequese: arranjos do período colonial e imperial. In: PASSOS, Mauro (Org.). Uma história no plural: 500 anos do movimento catequético brasileiro. Petrópolis: Vozes, 1999.

AZZI, Riolando; GRIJP, Klaus van der. História da Igreja no Brasil: ensaio de interpretação a partir do povo. Terceira Época. Petrópolis: Vozes, 2008, p. 223-224.

BORRMANN, Ricardo Gaulia. Tal mercado, tal príncipe: o paradigma da perfeição na economia política burguesa. Niterói, 2009. Dissertação (Mestrado em Ciência Política) - Instituto de Ciências Humanas e Filosofia, Universidade Federal Fluminense, Niterói. 2009.

BOURDIEU, Pierre. A dissolução do religioso. In: BOURDIEU, Pierre. Coisas Ditas. Rio de Janeiro: Brasiliense, 1990.

CORREIO DA MANHÃ. Rio de Janeiro, 11 de outubro de 1929, p. 3, col. 3. [Acervo da Biblioteca Nacional]. Disponível em: <http://memoria.bn.br/DocReader/089842 03/42536?pesq=0s\%20sacrilégios\%20do\% 20liberalismo>. Acesso em: 20 abr. 2020.

CORREIO PAULISTANO. São Paulo, 28 de dezembro de 1929, p. 5, col. 3. [Acervo da Biblioteca Nacional]. Disponível em: <http://memoria.bn.br/DocReader/090972_07/39339?pesq=Julio\%20Prestes\%20igreja >. Acesso em: 20 abr. 2020.

CRÍTICA. Rio de Janeiro, 13 de outubro de 1929, p. 3, col. 3. [Acervo da Biblioteca Nacional]. Disponível

em: <http://memoria.bn.br/DocReader/372382/2110?pesq=julio\%20prestes>. Acesso em: 20 abr. 2020.

DIÁRIO CARIOCA. Rio de Janeiro, 27 de maio de 1929, p. 1, col. 3. [Acervo da Biblioteca Nacional]. Disponivel em: <http://memoria.bn.br/docreader/093092 01/3100?pesq=divorcio\%20a\%20vinculo>. Acesso em: 20 abr. 2020.

DIÁRIO CARIOCA. Rio de Janeiro, 22 de Setembro de 1929, p. 2, col. 5. [Acervo da Biblioteca Nacional]. Disponível em: <http://memoria.bn.br/DocReader/093092 01/4033?.pesq=\%22divorcio\%20Julio\%20Pr estes\%22>. Acesso em: 20 abr. 2020.

DIÁRIO CARIOCA. Rio de Janeiro, 19 de outubro de 1929, p. 4, col. 2. [Acervo da Biblioteca Nacional]. Disponível em: <http://memoria.bn.br/DocReader/093092 01/4283?pesq=Getulio\%20Vargas\%20cat ólico>. Acesso em: 20 abr. 2020.

DIÁRIO NACIONAL: A Democracia em Marcha. São Paulo, 17 de Outubro de 1929, p. 8, col. 3. [Acervo da Biblioteca Nacional]. Disponível em: 


\section{hydra}

<http://memoria.bn.br/docreader/213829/7950?pesq=\%22Julio\%20Prestes\%20>.

Acesso em: 20 abr. 2020.

DIÁRIO MERCANTIL. 16 de setembro de 1929, p. 1, col. 1-2. [Arquivo Histórico da Cidade de Juiz de Fora].

DIÁRIO MERCANTIL. 1 de novembro de 1928, p. 1, col. 1-2. [Arquivo Histórico da Cidade de Juiz de Fora].

FAUSTO, Boris. A Revolução de 1930 - História e historiografia. 16 ed., São Paulo: Companhia das Letras, 1997.

FIGUEIREDO, Luciano Raposo de Almeida. Barrocas Famílias: a vida familiar em Minas Gerais no século XVIII. São Paulo: Hucitec, 1997.

FUNDO BR SPAPESP JPA - Júlio Prestes de Albuquerque. Arquivo Público do Estado de São Paulo, São Paulo, 2016.2 Disponível em: http://icaatom.arquivoestado.sp.gov.br/ica-atom/index.php/julio-prestes-2;isad>.

Acesso em: 20 abr. 2020.

GALANTE, Rachel de Souza. O punhal da fé: idéias políticas, jurídicas e religiosas sobre o casamento civil no Segundo Reinado. Niterói, 2008. Dissertação (Mestrado em História) - Instituto de Ciências Humanas e Filosofia, Universidade Federal Fluminense, Niterói. 2008.

GOMES, Ângela Maria de Castro; FERREIRA, Marieta de Moraes. Primeira República: um balanço historiográfico. Revista Estudos Históricos, Rio de Janeiro, v. 2, n. 4, p. 244280, dez. 1989. ISSN 2178-1494. Disponível em: <http://bibliotecadigital.fgv.br/ojs/index.php/reh/article/view/2287/1426>. Acesso em: 19 Abr. 2019.

GOMES, Francisco José da Silva. Quatro séculos de cristandade no Brasil. In: Seminário Internacional de História das Religiões. Associação Brasileira de História das Religiões, Recife. Anais... Recife, 2001. (digitado).

HESPANHA, Antônio Manuel. Carne de uma só carne: para uma compreensão dos fundamentos histórico-antropológicos da família na época moderna. Análise social Revista do ISCTE, Lisboa, n. 123-124, v. XXVIII, 1993.

LEBRUN, François. O sacerdote, o príncipe e a família. Lisboa: Terramar, s/d.

LUNA, Naara. A controvérsia do aborto e a imprensa na campanha eleitoral de 2010. Caderno CRH, Salvador, v. 27, n. 71, p. 367-391, ago. 2014. Disponível em: <http://dx.doi.org/10.1590/s0103-49792014000200010>. Acesso em: 19 abr. 2019.

MAINWARING, Scott. Igreja Católica e política no Brasil (1916-1985). São Paulo: Brasiliense, 2004, p. 41.

NEDER, Gizlene; CERQUEIRA FILHO, Gisálio. Idéias jurídicas e autoridade na família. Rio de Janeiro: Revan, 2007.

O DIA. 20 de julho de 1920, p. 1, col. 2. [Setor de Memória da Biblioteca Municipal Murilo Mendes].

O DIA. 05 de fevereiro de 1921, p. 1, col. 1-2. [Setor de Memória da Biblioteca Municipal Murilo Mendes].

O DIA. 02 de setembro de 1921, p. 1, col. 6. [Setor de Memória da Biblioteca Municipal Murilo Mendes].

O DIA. 07 de julho de 1921, p. 1, col. 1-2. [Setor de Memória da Biblioteca Municipal Murilo Mendes].

O DIA. 28 de junho de 1929, p. 2, col. 2. [Acervo da Biblioteca Nacional]. Disponível em: $\quad<$ http://memoria.bn.br/DocReader/092932/15148?pesq=celso\%20bayma $>$. Acesso em: 20 abr. 2020. 


\section{hydra}

PINTO, Jefferson de Almeida. Os lazaristas e a política imperial - uma escola, uma assistência e a família. Topoi, Rio de Janeiro, v. 17, n. 32, p. 153-175, jun. 2016. Disponível em: <https://www.scielo.br/pdf/topoi/v17n32/2237-101X-topoi-17-3200153.pdf>. Acesso em: 29 jun. 2020.

RAMOS, Henrique César Monteiro Barahona. A revista $O$ Direito - periodismo jurídico e política no final do Império do Brazil. Niterói, 2009. Dissertação (Mestrado em Sociologia e Direito) - Instituto de Ciências Humanas e Filosofia, Universidade Federal Fluminense, Niterói. 2009.

RODRIGUES, Fabiana Cardoso Malha. Idéias jurídicas famílias e filiação na passagem à modernidade no Brasil, 1890-1940. Niterói, 2008. Tese (Doutorado em História) Instituto de Ciências Humanas e Filosofia, Universidade Federal Fluminense, Niterói. 2008. 287 págs.

ROMANO, Roberto. Brasil Igreja contra Estado. São Paulo: Kairós, 1979.

SILVA, Ana Paula Barcelos Ribeiro da. Diálogos sobre a escrita da história. Brasil e Argentina (1910-1940). Ibero-americanismo, catolicismo, cooperação intelectual, (des)qualificação e alteridade. Brasília: Fundação Alexandre de Gusmão, 201 1, p. 178.

VENÂNCIO, Renato Pinto. Famílias abandonadas: assistência à criança de camadas populares no Rio de Janeiro e em Salvador - séculos XVIII e XIX. Campinas: Papirus, 1999.

VISCARDI, Cláudia Maria Ribeiro. O teatro das oligarquias: uma revisão da "política do café com leite". 2.ed., Belo Horizonte: Fino Traço, 2019. [E-book].

Artigo recebido em 14/07/2020 e aprovado em 20/01/2021 